\title{
NOAA CLIMATE DATA STEWARDSHIP: PROGRESS THROUGH PARTNERSHIPS
}

\author{
Robert J. Leffler, Michael J. Brewer, Robert E. Livezey, \\ Robert W. Reeves, Myron Berger, \\ Climate Services Division, Office of Climate, Water, and Weather Services \\ NWS/NOAA, Silver Spring, MD
}

Timothy W. Owen and Karsten Shein

National Climatic Data Center/NESDIS/NOAA, Asheville, NC

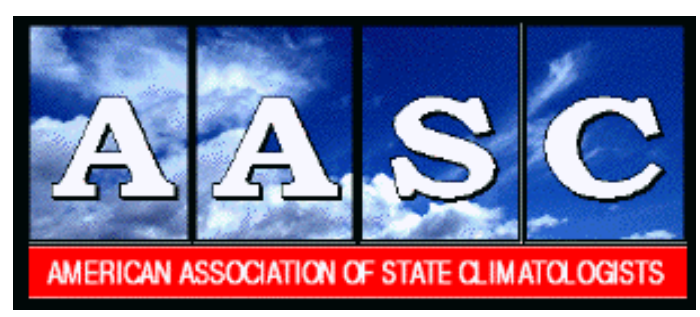

2007

Journal of Service Climatology

Volume 1, Number 3, Pages 1-14

A Refereed Journal of the American Association of State Climatologists 


\title{
NOAA Climate Data Stewardship: Progress Through Partnerships
}

\author{
Robert J. Leffler, Michael J. Brewer, Robert E. Livezey, \\ Robert W. Reeves, and Myron Berger \\ Climate Services Division, Office of Climate, Water, and Weather Services
NWS/NOAA, Silver Spring, MD
}

Timothy W. Owen and Karsten Shein

National Climatic Data Center/NESDIS/NOAA, Asheville, NC

Corresponding author: Robert J. Leffler, W/OS4, Climate Services, Rm. 13352, SSMC 2, 1325 East

West Highway, Silver Spring, MD 20910, USA. Tel: 1-301-713-1970, ext. 134, Fax: 1-301-713-

1520, Robert.Leffler@noaa.gov

Editor's Note: This is an invited review paper on the state of service climatology.

\begin{abstract}
Recent changes in the organizational structure of the National Oceanic and Atmospheric Administration (NOAA) have created an environment conducive to improved end-to-end agency climate data stewardship. Changes include the reintroduction of a climate services program into the National Weather Service (NWS) through the creation of a Climate Services Division (CSD) at the headquarters level, the creation of a NWS liaison at the National Climatic Data Center (NCDC), and the addition of six Regional Climate Centers as contractual support for NCDC.

Action is being undertaken to mitigate deficiencies identified in the current surface weather and climate data collection, quality control, and dissemination process. Central to the effort in improving NOAA's end-to-end data stewardship process is the strengthened partnerships and related coordination and collaboration between these different organizations.

Strengthened partnerships, data policy changes, staff training in climate principles, and more effective operational practices ensure compliance with climate community needs and pay immediate dividends through increased data quality and data availability for all users.

The evolution and changes noted above are
\end{abstract}

documented. Future agency priorities for additional improvements that further protect the integrity of the nation's climate record are also discussed.

\section{Introduction}

Interest in accurate and timely weather and climate observations has grown tremendously over the past decade. Currently, it is estimated that \$3 Trillion of the U.S. gross domestic product is associated with industries sensitive to weather and climate impacts (Dutton, 2002). The U.S. has experienced numerous multi-billion dollar weather disasters in the last 15 years (Lott and Ross, 2006). Additionally the Intergovernmental Panel on Climate Change (2007) reports that trillions of dollars of decision making now depends on the conclusions of climate change assessments. The demand for high quality weather and climate data continue to increase.

As the customer-perceived neutral broker for climate data services, the National Oceanic and Atmospheric Administration's (NOAA) data stewardship mission, including the timely delivery of accurate, secure, and consistent weather and climate data, has never been more critical. NOAA is the lead federal agency with the responsibility for the collection, quality control, archiving, and dissemination of surface 
climate and weather observations. These data are used by the agency to fulfill its mandate to describe the nation's climate and detect, monitor and predict climate variability and change, including characterization of socio-economic impacts. Assuring data quality at the point of observation and throughout the data management process is crucial.

NOAA's surface weather and climate data stewardship responsibility is split between the National Weather Service (NWS) and the National Environmental Satellite, Data, and Information Service (NESDIS). NWS establishes and maintains observation networks and instrumentation, collects the preliminary data, makes that data available to users, and delivers the data to NESDIS's National Climatic Data Center (NCDC). NCDC quality-controls, archives, and disseminates the data in a variety of formats and as specific products. Since its founding in 1951, NCDC has served as the sole federal organization authorized to certify NOAA climate data for users.

NWS and NESDIS each have clearlydefined responsibilities that have historically been fulfilled independent of one another. Inevitably, this split in responsibilities led to some ambiguities and inefficiencies in the agency's data management process. The user community raised a number of concerns in the areas of data collection efficiency, timely availability, integrated data quality control procedures, accuracy, data base consistency and security, and called for action to address the issues, which necessitated a re-examination of coordination (Murnane et. al, 2002).

The subsequent organizational changes and the evolution of the partnerships are described in section 2, followed by examples of progress in data collection, quality control and dissemination in section 3. The paper concludes with a brief summary of the partnership and implications for the future.

\section{Organizational Changes and Partnerships}

NOAA is responding to customer concerns first through implementation of three organizational changes:

1) In 1997, six Regional Climate Centers (RCC) were placed through contract, under NCDC oversight.

2) In 2000, NWS Headquarters established a Climate Services Division (CSD) to reestablish and strengthen climate services in NWS. (NWS, 2003; NWS, 2006b).

3) In 2003, NCDC established a liaison position to collaborate closely with NWS on common objectives.

These changes combined to set the stage for significant change. The proactive partnerships between NCDC and the RCCs resulted in enhancements in three basic data-related activities that focused on data collection from insitu surface weather and climate observation networks maintained by the NWS:

- Data collection: through observing network enhancements and compliance with climate monitoring principles

- Data quality control: using data analysis tools and ensuring coordination with the other climate services partners

- Data dissemination: from enhanced and timely observer data entry to improved web based disseminations systems and coordination with climate services partners

The need for partnerships between the government, academic and the private sector for the effective delivery of climate data is well documented (NRC, 2003). These partnerships existed loosely before NWS and NCDC organizational changes occurred. Prior to the changes, many of the data stewardship activities were conducted in parallel with little coordination or integration. For example, although a great deal of data quality control was being conducted by NCDC, the NWS (Weather Forecast Offices (WFO), River Forecast Centers (RFC), Climate Prediction Center (CPC), Meteorological Assimilation Data Ingest System (MADIS)), the RCCs and State Climatologists (SC) were also conducting data quality control independently. The result was multiple data sets with inconsistent and disparate data. Organizational changes have addressed this and other issues leading to improvements in data stewardship.

CSD developed an overall strategy to nurture much stronger cooperation with NCDC and the RCCs, academia, other parts of the private sector, and the American Association of State Climatologists (AASC). The strategy included implementing climate services in the NWS field, including full-time staff in each of the six NWS regional headquarters and trained, part-time position at each of the 122 WFOs, 13 RFCs, and 19 Weather Service Offices (WSOs). NWS further ingrained NCDC and RCC developed enhancements in data-related activities 
into its operations.

The new robust partnership coordination process is illustrated in Figure 1. NWS and partner-collected data and information are passed to the NCDC and the RCCs. Data quality control and value-added products and services are then produced and provided to NOAA's user community. Partners share in research and assessment activities, and requirements for advanced field practices and other product development concepts are vetted through NWS and the partners as appropriate. While this partnership cycle is evolving, it represents a general framework for future collaboration with other government partners.

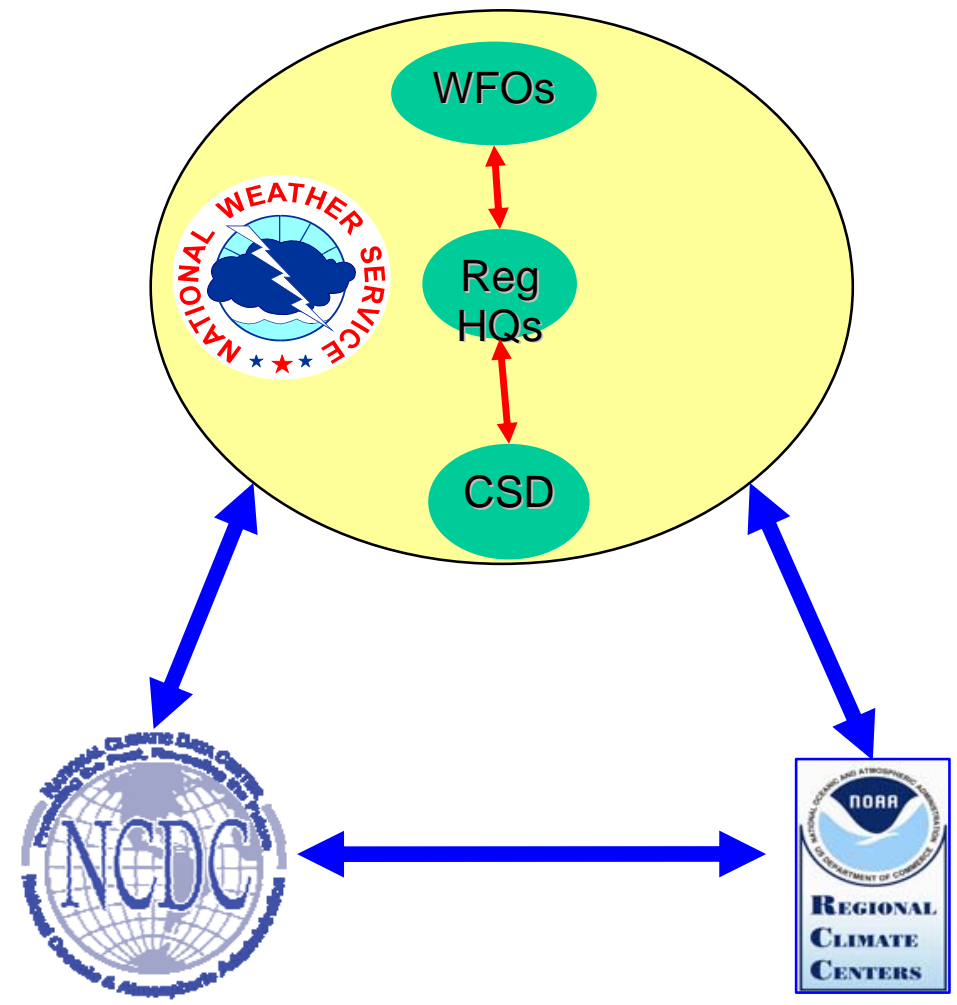

Figure 1: The NOAA Climate Services Partners.

\section{Progress}

While the partnerships themselves are an improvement in the way business is conducted, progress is measured by accomplishments. NOAA data stewardship improvements resulting from improved partnerships and reorganization have occurred primarily in the areas of data collection, data quality control, and data dissemination.

While partnerships can be improved and policies can be put in place, it is the training of the workforce serving as the customer interface that leads to improved operational practices. NWS, working with NCDC, ingrained climate data stewardship into its Professional Development Series through a number of Professional Competency Units (PCU). This training, targeted toward NWS climate services focal points in the WFOs, provides both the background and details applied to operations, to

ensure that climate data services are provided consistently and accurately at the local level.

Training focuses the ten principles of climate monitoring (Karl et al. 1996) for weather 
network operation and includes topics such as:

- Demonstrate Knowledge of the Infrastructure for Climate Data and Services

- Respond to User Requests for Historical Climate Data and Information, and Provide Public Outreach

- Demonstrate Knowledge of Timely, Accurate, and Consistent Climate Observations

- Applying the Ten Principles of Climate Monitoring

- Factors Affecting the Accuracy and Continuity of Climate Observations

- NOAA Applications of Climate Data

- Non-NOAA Applications of Climate Data

Training is available in a variety of formats including residence courses and web- and teletraining. It is freely available to partners and the public on the NWS Climate training website (http://www.nws.noaa.gov/om/csd/pds/index.htm l).

While training lays the foundation for the collection of climate quality data, it must be supported by observing policy and applied operationally. In order to do this, many changes needed to be implemented.

\subsection{Data Collection}

Progress in data collection primarily has been the result of improvements in the eight areas described below. Together, they result in a major shift in NOAA focus ensuring the integrity of the climate record through improved data collection.

\subsubsection{Continuity of Observations}

Climate data monitoring principles require parallel observations when network changes (e.g., replacing sensors, moving stations, environmental change, etc.) are made that can introduce artificial data discontinuities. Policy was implemented to address this. As a result, NWS maintained in-situ observing networks now require the systems to be operated in compliance with the ten principles of climate monitoring (NWS 2005a), including conducting parallel observations under certain conditions for Cooperative Observer Program (COOP), Automated Surface Observing System (ASOS), and the upper air networks. Compliance with this new policy allows NOAA and other data users to correct for artificially induced climate data discontinuities, allowing more accurate analyses of climate change and variability.

\subsubsection{Relocated Station Numbering}

NWS's methods for determining the identification number for a station that has been relocated required updating to bring them into compliance with climate continuity principles. Current practices allow retention of a station number for any move within 100 vertical feet and/or five horizontal miles of the original location. Analyses clearly show that for most relocations within these distances, the climate record from the new site is significantly different than the original site (Reeves, 2006; Redmond, 2006). By retaining the identification number, the key metadata tag for station identification, the climate record for the station would contain an artificial data discontinuity that would be undetected by most data users and could mistakenly lead to an incorrect conclusion about trends. To address this problem, NWS is providing new guidelines on station numbering in its forthcoming update to COOP Operations Manual (NWS, 1993). These guidelines place the burden of retention of a station identification number on a rigorous demonstration of climate data continuity regardless of horizontal and vertical distance changes involved in the relocation. The new policy will result in reduced artificial inhomogeneties in specific station data sets.

\subsubsection{Backup Site Data}

NWS received numerous complaints from customers regarding mismatched hourly and daily/monthly totals of precipitation at certain Local Climatological Data (LCD) stations, a subset of ASOS used for climate purposes. WFOs were, on occasion, including data from manual backup precipitation stations, often located miles away from the primary LCD equipment to augment the station record without documentation. Recent changes to NWS operational practices allow NOAA-published LCD sites to use backup site data only when primary instrumentation is either not functioning or when, in the judgment of the WFO staff, the primary LCD report is incorrect (NWS, 2006a). The new policy requires that the date, location of backup instrument, and element being backed up be noted on the preliminary monthly climate form (F-6) as well as be included in the final NCDC LCD publications. Compliance allows data users to see instances where LCD data are inconsistent and a backup site was used. 


\subsubsection{Estimation of Missing Data}

In the past, the estimation of missing data by WFO staff was handled inconsistently. While some offices provided estimates of missing values, others did not. Additionally, among those that did provide estimates, methods were not standardized between offices or even within an office. Estimation methods were undocumented. National policy was changed to ensure national uniformity. It was determined that the best approach to estimating missing data was to make estimates in a post-observation environment where numerous complementary data sets (surrounding in-situ data, remote sensing, range checks, etc.) could be utilized in a more robust fashion to produce traceable, repeatable results. This approach is best conducted at NCDC, the NOAA line office whose mission includes final data quality control. New policy now instructs NWS WFOs not to estimate missing data (NWS, 2006a). Estimations are left to the discretion of NCDC. The result is an improved climate record with standardized estimated missing data values.

\subsubsection{Electronic Communication of Manual Observations}

One of the most significant changes underway for data collection is the COOP data "paperless" initiative. This activity expands on existing NWS regionally developed telephone and web-based systems to create a nationallysupported electronic COOP data collection system. Data are collected via either system and the observations populate the same database. The system employs redundant backup of both the public interfaces and the database. Plans call for the web-based part of the paperless initiative (Web Xmitted COOP Observer Data Encoded Report or wxCODER) to be operational by late 2007 in the RCCs with support from NCDC (Figure 2). Upgrades to the telephone based system (Interactive Voice Remote Observation Collection System or IVROCS) will follow in 2008 with operations in NWS.

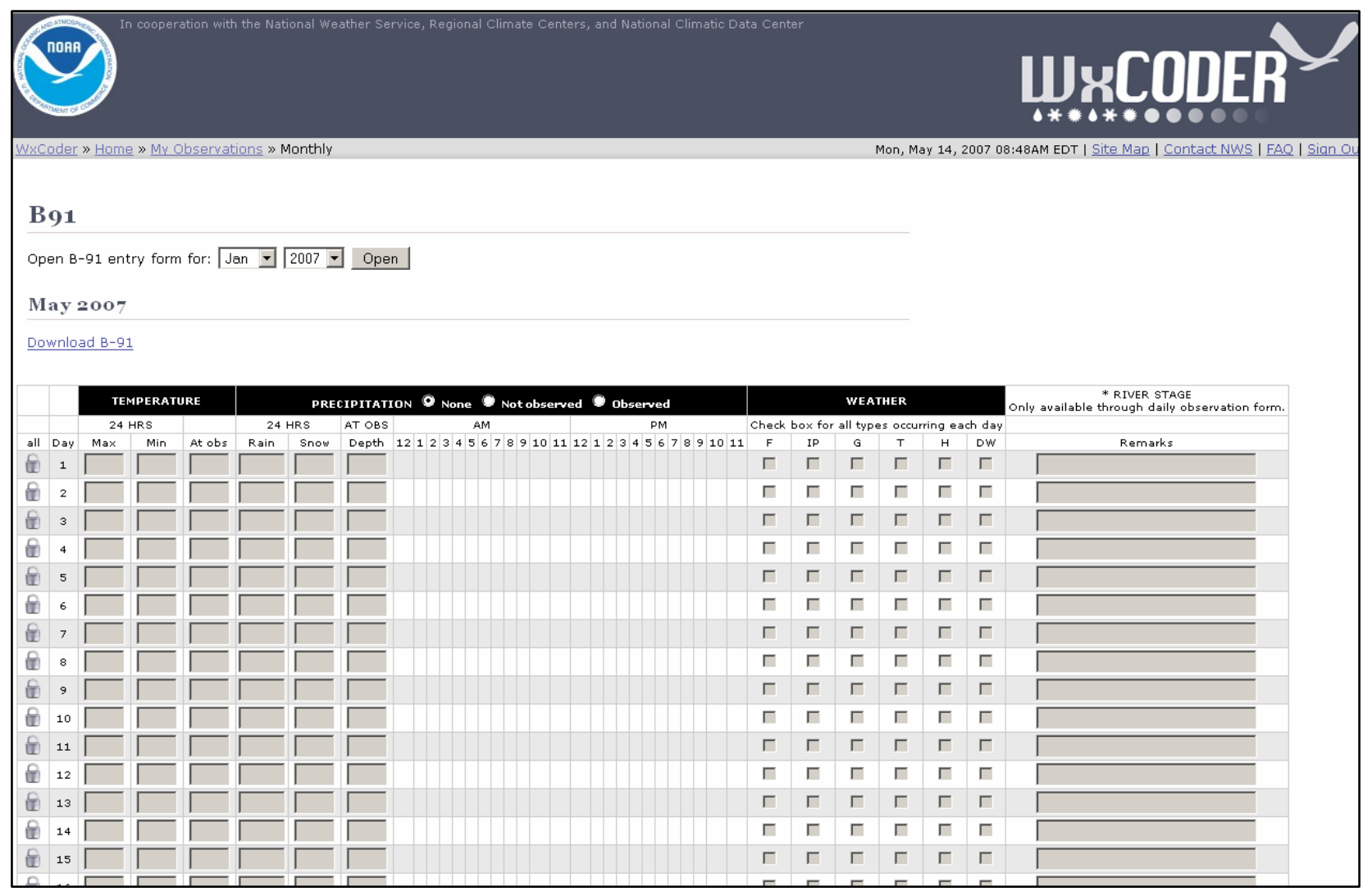

Figure 2. Recreation of Monthly B-91 for observer entry in wxCODER. 
Benefits of the electronic collection systems include greatly enhanced data quality at the point of observation entry, automated electronic data collection and dissemination for NWS forecast applications, daily data availability, and electronic transmission to NCDC for timely data quality control and data availability. Extensive quality control at the point of observer entry will eliminate errors inherent in current manual recording, transcription, and transmission practices. Chief among these are:

- Format errors: Paperless will force observations to be provided using correct format. For example, a precipitation report will require the data be provided to 0.01 inches. It will also make sure that if snowfall is indicated in the observation that liquid equivalent of frozen precipitation is also provided.

- Value errors: Paperless will provide an initial cut at reducing value errors common in transcription. Extremes appropriate for each station or region will be entered into the system and values provided by observers will be checked against these extremes, as well as be subjected to internal consistency checks. If checks identify a potential error, the observer will be prompted to confirm or will be contacted by the local WFO. Checks for value errors will eliminate errors such as a 750 degree maximum temperature rather than 75.0 (format errors will ensure the 75.0 degrees becomes 75 degrees).

While it is anticipated that it will take several years to transition most COOP observers over to the electronic data collection systems, this improvement will result in thousands of additional COOP stations' data being available on a daily basis. These data will become the official climate record. The integrity of the climate record will also be improved as a result of the extensive up-front data quality control which will work in conjunction with other practices conducted after observer submission, such as geographical station comparisons and corrections (see section 3.2).

\subsubsection{Backup Power for LCD in Hurricane-Prone Areas}

Critical wind and precipitation data from LCDs were being lost during tropical storms and other high wind events, mainly due to communications failures and electrical outages. This was especially evident in the course of many land-falling hurricanes of 2004 and 2005. Beginning in 2006, backup electrical power for 152 hurricane-prone LCD stations within 150 miles of the coastline were installed. Following completion of the backup power, critical hourly surface observation sites will experience less observation failure during extreme weather and there will be fewer instances of unrecoverable data after an event. The climate record will improve as a result as will the real-time monitoring and forecasting of tropical storms.

\subsubsection{Snowfall Measurements}

In 2003, snowfall measurements were in jeopardy of ceasing at all 261 LCD sites as a result of a transfer of manual weather observation duties from NWS staff to contract Federal Aviation Administration observers. Resources were obtained to support observation of this critical climatic element and ensure the continuity of data at these sites. This data provides snowfall reports from large metropolitan areas, serving, among others, critical service and transportation decision makers and federal disaster declarations.

\subsubsection{All Weather Precipitation Guage (AWPAG)}

NWS has begun to replace ASOS rain gauges that are incapable of accurately measuring the liquid equivalent of frozen precipitation with a new All-Weather Precipitation Accumulation Gauge (AWPAG). In the process, 20 of the LCD sites published by NOAA but sponsored by the Federal Aviation Administration (FAA) were overlooked and not funded to receive the upgrade. Agency funds were reprogrammed to ensure that all LCDs received the new, more accurate gauge. Data quality and the climate record will benefit as a result.

Although data quality begins at the point of the observation with the initial data collection, the data itself should always be subject to data quality checks to reduce the risk of inaccuracy. Progress in data quality control procedures are discussed in the next section.

\subsection{Data Quality Control}

Data quality control is one of the most important considerations in ensuring high data quality. This is especially true when the data are being collected to meet the rigorous, long-term needs of the climate record. While steps are being taken to address point-of-entry quality control through the "paperless" (section 3.1.5) the existing non-observer based data quality control process has many deficiencies. They include:

- A lack of rigorous standardized on-site quality control 
- Uncoordinated data quality control among multiple organizations

To address issues that have arisen across the agency in data continuity, numerous tools were developed to help identify, track, and resolve discrepancies. Further, these tools have been put into practice by the local stewards of the climate observations systems in the WFOs.

\subsubsection{Datzilla Data Error Tracking}

Reporting data discrepancies in NOAA's climate data archives has historically been performed on an ad hoc basis by NOAA and partners. Requests for corrections were sporadic partly because of the limited feedback and slow resolution of the problems. Datzilla (available at http://datzilla.srcc.lsu.edu/datzilla/), a web-based system for reporting and tracking data discrepancies and their resolution in historical NOAA data sets and products, was developed to correct these problems (Figure 3). It was developed by the RCCs utilizing existing internet technologies for reporting and tracking data discrepancies. Datzilla allows authorized error reporters (e.g., NWS Climate Services Focal Points (CSFP), Observations Program Leaders, Data Acquisition Program Managers; SCs; climate community partners) and data managers to resolve issues with observed climate data, data access systems, and metadata. Other benefits include enhanced communication allowing easier reporting of data discrepancies and monitoring the error reporting process to resolution. Through Datzilla, the reporter of a data discrepancy can have confidence that, if the appropriate information has been provided, the problem will be given attention in a timely manner and corrected as appropriate.

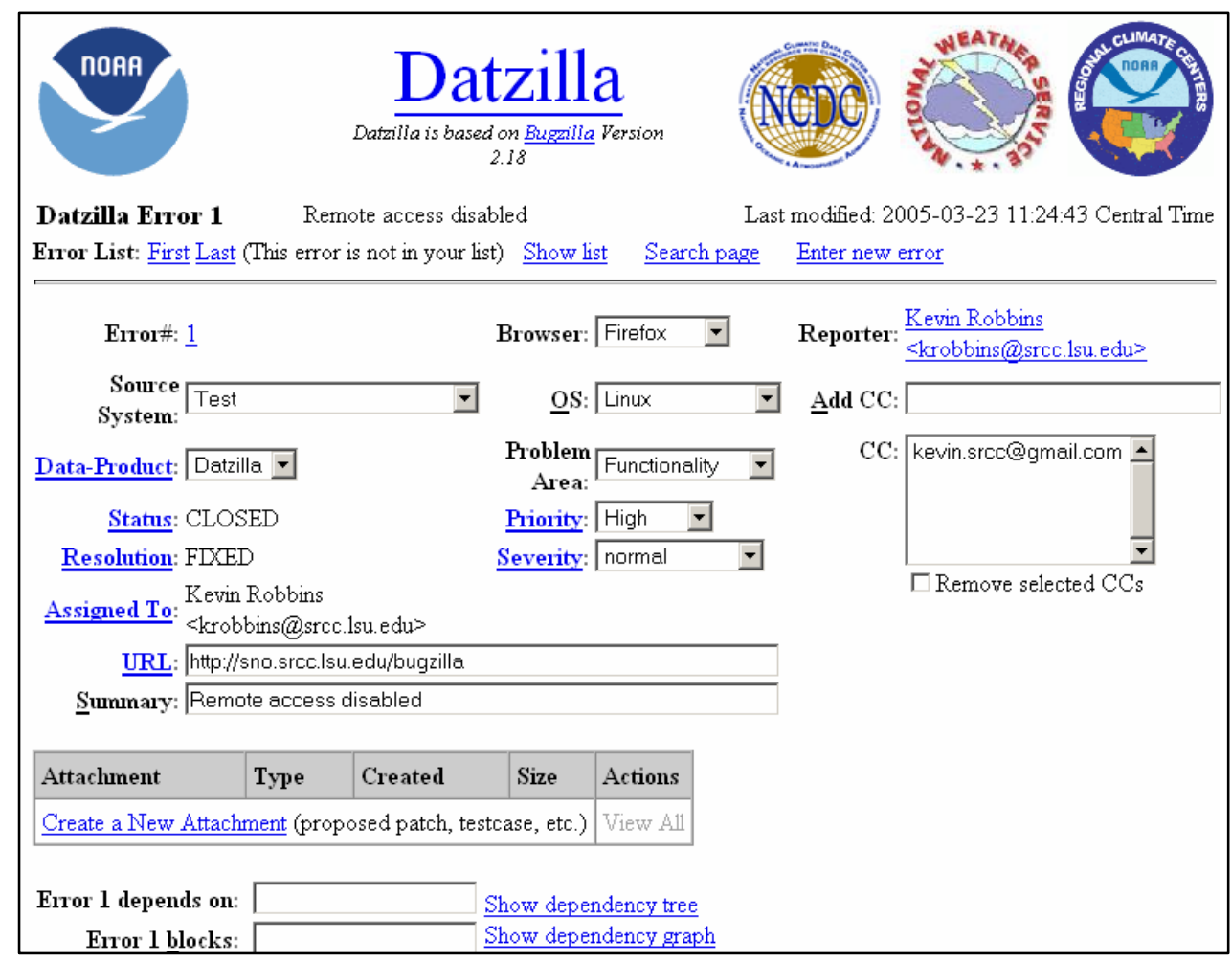

Figure 3. The Datzilla User Interface. 


\subsubsection{Web Search Store Retrieve Display}

NCDC's Web Search Store Retrieve Display (WSSRD) complements Datzilla for quality control. WSSRD provides over 40 million images of original observer submissions via the internet (Figure 4). Document images are organized by category and can be used to verify and/or correct the data discrepancies in the climate record.
Access to the original records allows rapid assessment of data discrepancies and further action where warranted to correct invalid data. Further, WSSRD has been ingrained in NWS climate services. Local staff regularly leverage WSSRD to supplement data corrections, often accomplished through Datzilla.

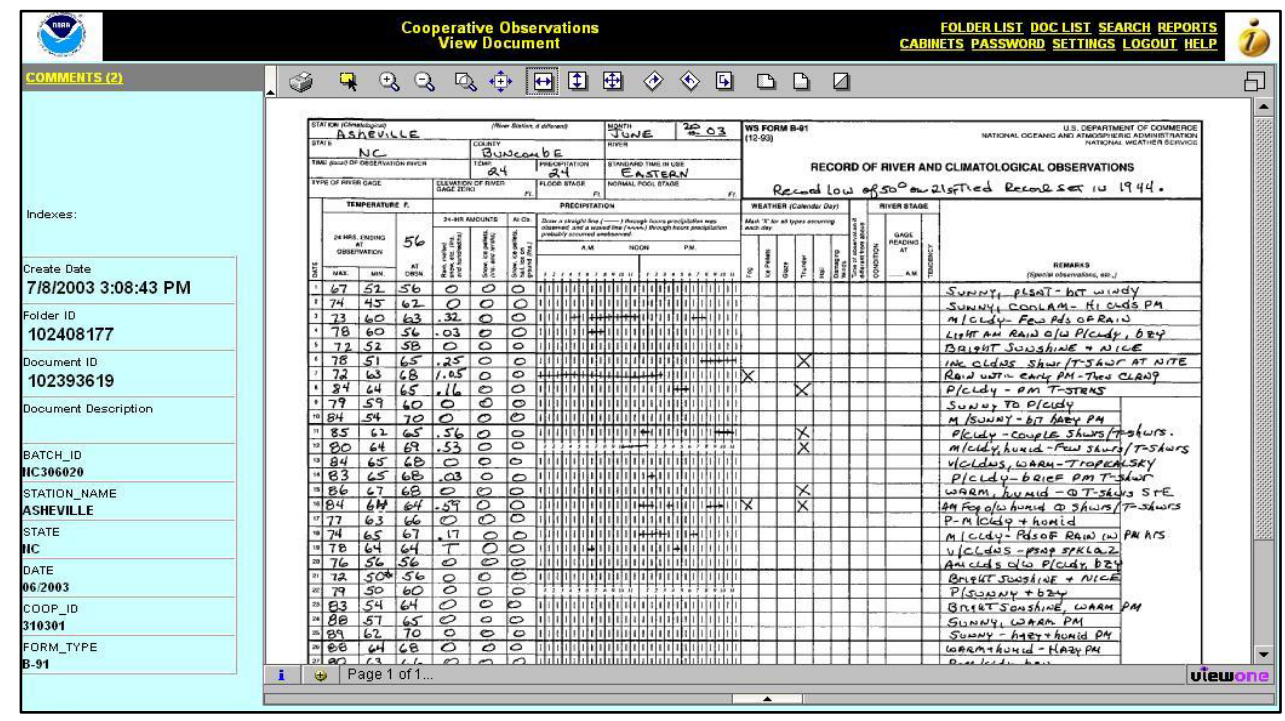

Figure 4. Image of an Original Monthly COOP Climate Record from WSSRD.

\subsubsection{Health of the Networks}

The Health of the Networks (HoN) allows quality control of observations varying in scale from complete observing systems to individual station observers. HoN analyzes reports from NOAA observing systems and provides a set of measures for monitoring their performance. These performance measures, including data completeness, quality, and validity as well as period of record, missing stations, and receipt timeliness on a monthly basis (Figure 5). This allows NWS WFO staff to track and address shortcomings due to instrumentation or observer practices. 


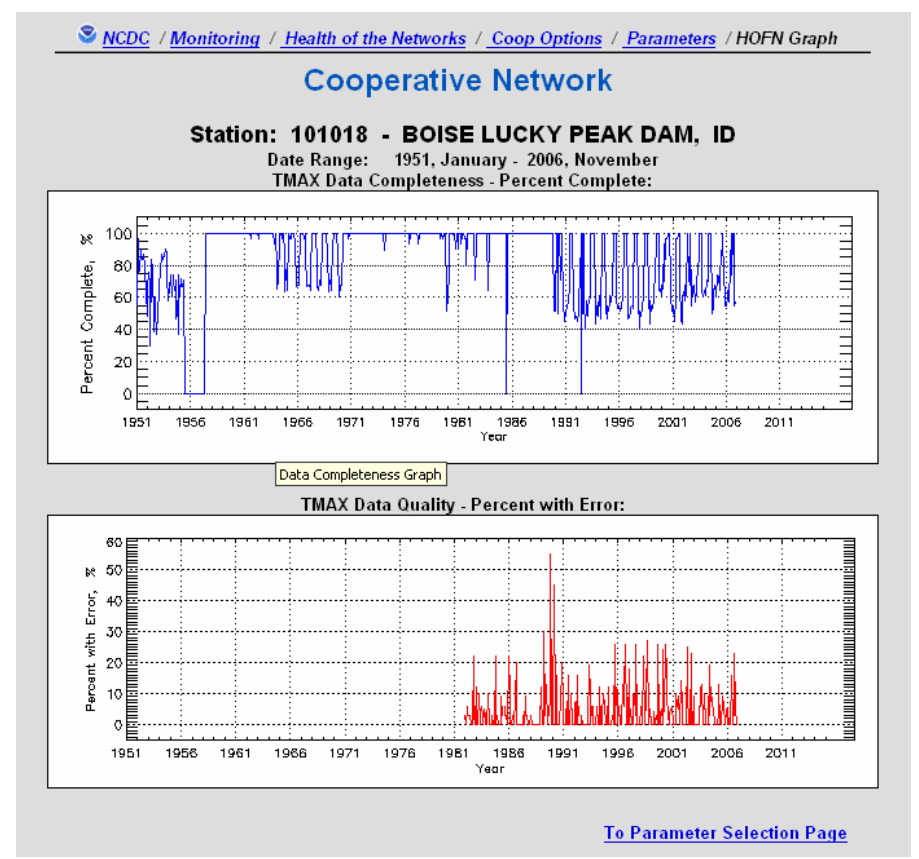

Figure 5. HoN Data Completeness Report.

\subsubsection{Snow Boards}

A fundamental mechanism for ensuring quality control of observations is the use of standard observing practices utilizing approved equipment. Snowfall is one of the more difficult meteorological measurements to take accurately and consistently because of drifting, settling, and wind redistribution. While NOAA's snowfall measurement standards require the use of a white snow measurement board, such boards had never been provided to observers. While some observers made their own boards, most took observations on grass, a picnic table, the roof of a car, or some other non-standard surface. The result was stationspecific biases that reduced the accuracy of area snowfall measurements. A requirement for the use of standard snow measurement boards was reestablished and these boards were provided for all published COOP stations in the nation.

The result of all these data quality control activities has been improvement in the consistency of the climate record. To leverage these quality control improvements to provide better services to partners and agencies relying on this data, changes were necessary to NOAA's climate data dissemination procedures.

\subsection{Data Dissemination}

Many of NOAA's partners and customers require timely receipt of data. NWS, NCDC, and RCC staff receive numerous customer inquiries for weather and climate data on a daily basis. Meeting this need has often been a challenge for NOAA. Improvements in data access for all users have resulted from changes made by the data stewardship partners.

\subsection{1 xmACIS}

NWS WFOs have a responsibility to provide information about their local area. Frequently, however, inquiries arise for information in adjoining or even distant areas. In the past, these inquiries were forwarded to NCDC or other appropriate partners, sometimes creating workload issues there. In an effort to address this problem, NWS, NCDC, and the RCCs developed xmACIS, a tool for WFO staff use that allows access to surface weather and climate information for the entire country (Figure 6). The system is based upon the Applied Climate Information System (ACIS), a national standardized database that is synchronized with the NCDC archives while still providing near real-time data up to the previous day. xmACIS also leverages development in the WFOs, in the form of xmCLIMATE, for search and analysis tools. With a few clicks of the mouse, service staff can provide data and information for almost any station in the country. In addition to improving the consistency and timeliness of customer service, WFOs 
benefited by no longer needing to maintain their own databases. In the past, each WFO maintained a separate database, often leading to inconsistencies in information for the same station, depending on when the database was updated.

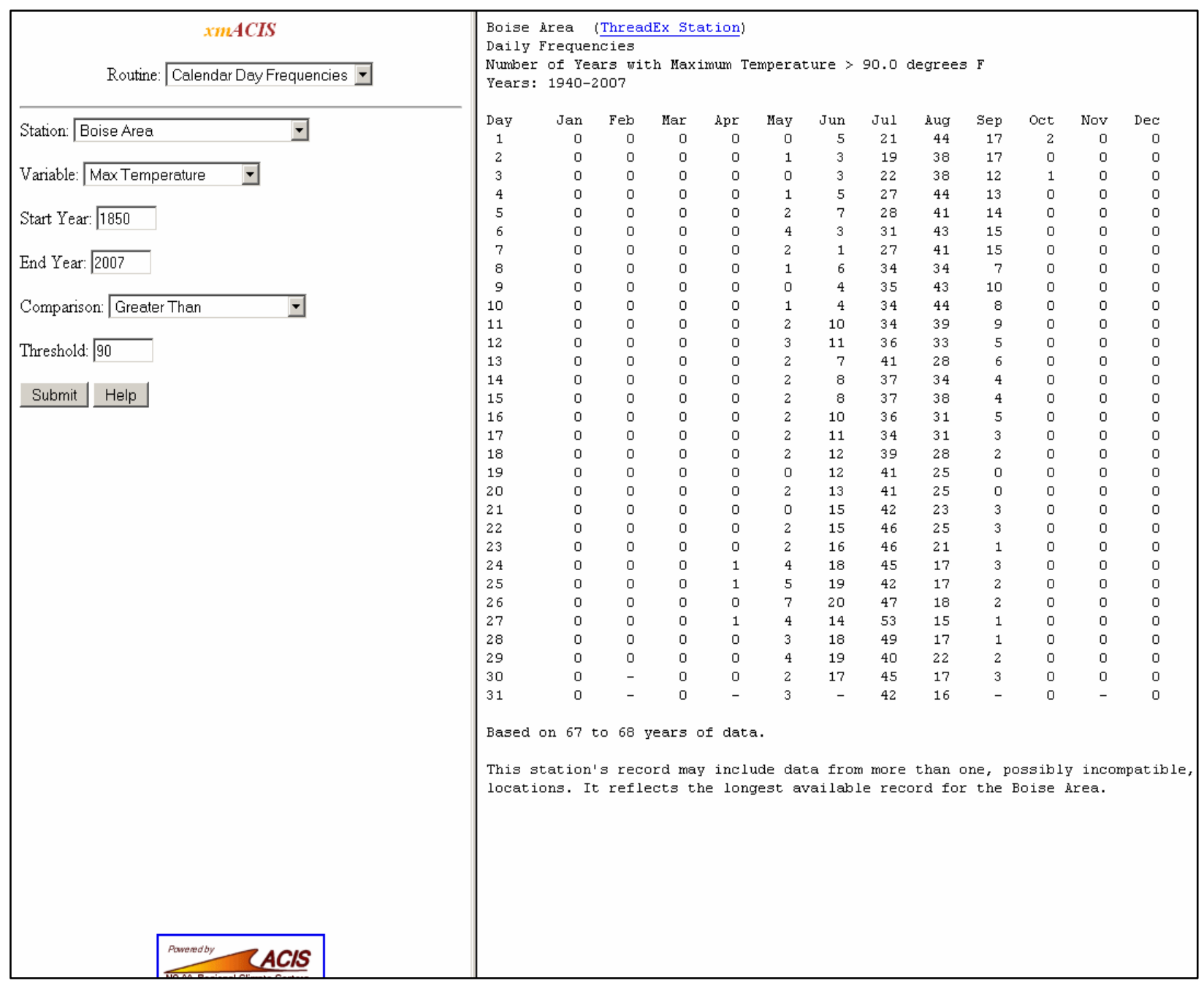

Figure 6. Results of xmACIS Data Inquiry.

\subsubsection{NOAA Online Weather Data}

NOAA Online Weather Data (NOWData) was developed in response to the increasing demand for climate data from the public (Figure 7). NOWData is a free, web-based self service tool providing access to a subset of the data and functionality available through xmACIS (available freely via www.weather.gov/climate). Users can access a wide range of climate products for nearly 4,000 locations nationwide and includes daily and monthly climate data for the last two years, climate averages for the "normal" 30-year period (19712000), and extremes for the entire period of record. NOWData greatly increases the public's ability to acquire climate data on demand in a standardized location across NWS websites. 


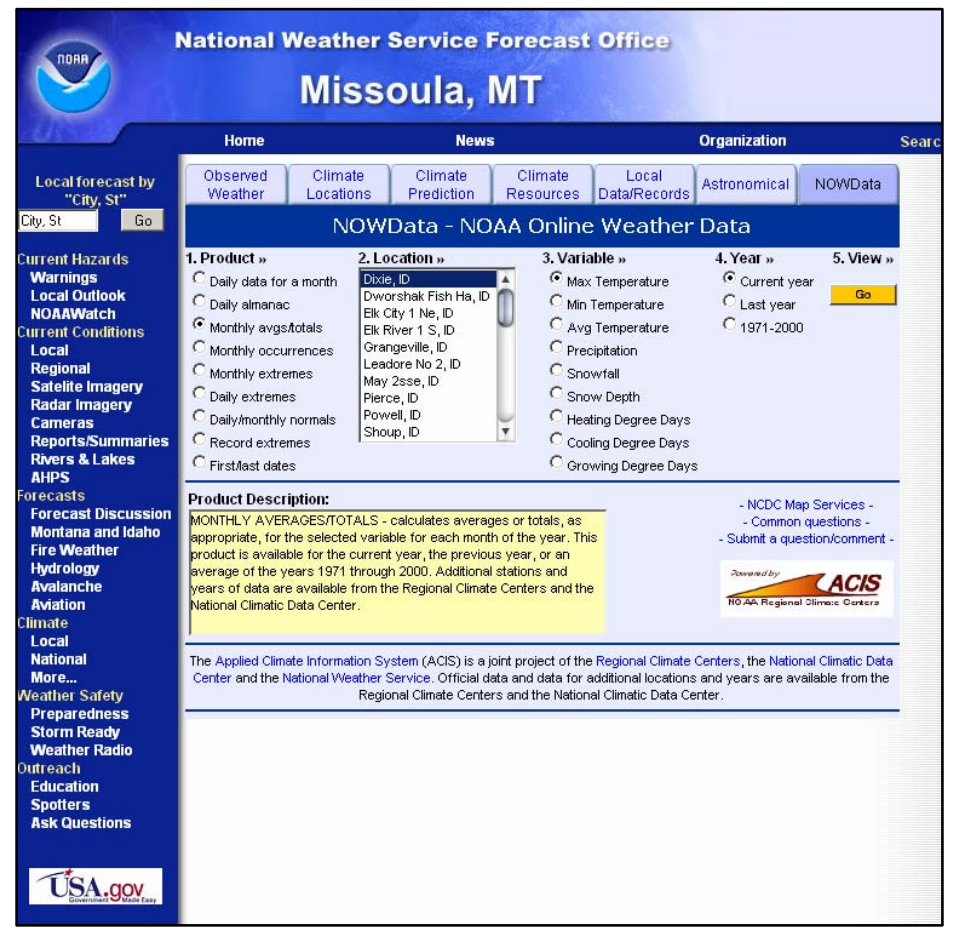

Figure 7: NOWData Public Web Interface.

\subsubsection{Threaded Extremes of Climate Data}

The Threaded Extremes of Climate Data project (ThreadEx - available through http://threadex.rcc-acis.org/) provides consistent NOAA information specifically for the public and media partners (Figure 8). ThreadEx was developed after it became apparent that different NOAA data sets were being used to provide information about climate extremes in large metropolitan areas. ThreadEx further addresses the fragmentation of station information over time due to station relocations and corrects these problems by piecing together long histories of climatologically-compatible stations in an area. This "threaded" data becomes the official record for comparing current data against extremes and provides consistent information for all customers. ThreadEx is currently loaded in xmACIS and NOWData and is in the process of being loaded into other databases for official NOAA data products. 


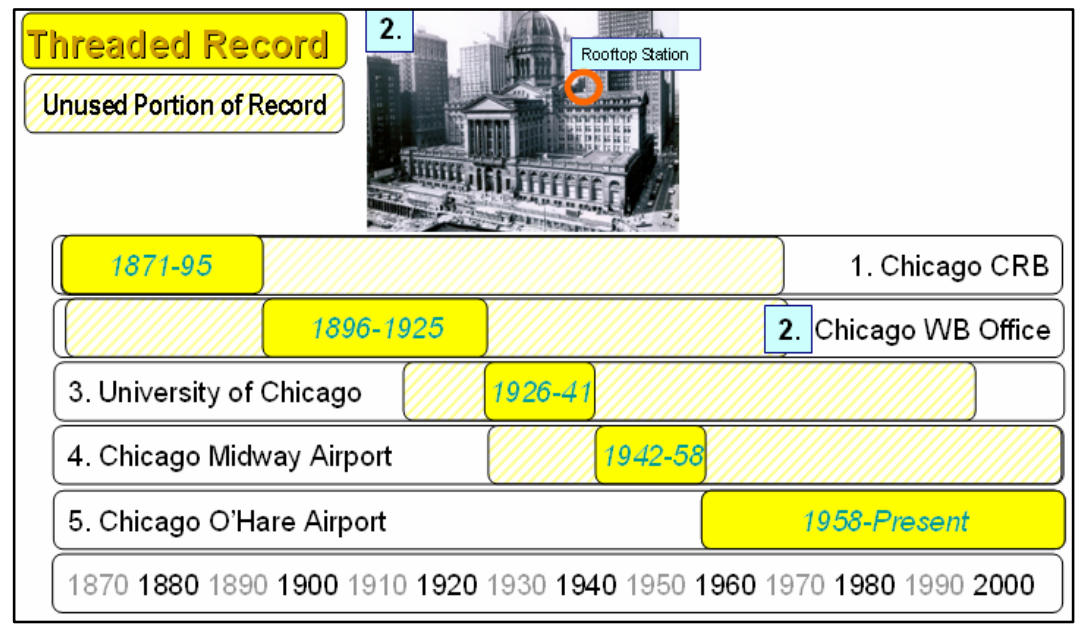

Figure 8: ThreadEx Station Threads for Chicago, IL Metropolitan Area.

\subsubsection{Consistent Data Dissemination}

In addition to user-generated issues, inconsistent data dissemination practices among NWS field offices generated concerns over compliance with existing legislative mandates related to data dissemination policy (Public Law 95-367, 1978; Public Law 100-685, 1988; Public Law 101-606, 1990). In response to these concerns, NWS developed data dissemination policy to ensure uniformity in services to customers and compliance with existing data cost recovery laws (NWS 2005b). Since legislative mandates require the agency to recover certain data services costs of NCDC products and services, NWS field office compliance with these policies now results in nationally standardized data dissemination services for all customers.

\section{Future Priorities}

While much progress has been made in the areas of data collection, quality control, and dissemination, much more needs to be done. To ensure that the recently created momentum for improved data stewardship continues, plans already exist for several additional projects.

\subsection{National Integrated Drought Information System}

At the request of, and addressing recommendations by, the Western Governors' Association (WGA), NOAA is leading the development and implementation of the National
Integrated Drought Information System (NIDIS). Through partnerships with other agencies, states, tribes, academia, and the private sector, NIDIS focuses on reducing the U.S. regional vulnerability to drought through a concentrated effort of research, observations, products, tools, forecast development, communications, and stakeholder support. Initial improvements in NOAA climate services related to NIDIS will focus on expanded observations of soil moisture and temperature by the Climate Reference Network, and a central clearinghouse, or portal, for nation-wide drought information. These and future activities will lead to improved products such as a next generation Drought Monitor and Drought Outlook and may include upgrades for the COOP network, in the areas of timely reporting and quality assurance.

\section{2. $21^{\text {st }}$ Century COOP Network}

Improvements to COOP are a high priority for NOAA. While budget constraints have precluded full COOP modernization, a plan has been developed to sustain and transform COOP into an efficient $21^{\text {st }}$ century weather and climate observing network (NWS, 2007). The plan, scheduled for implementation beginning in late 2007, focuses on heightened data quality and network maintainability in an effort to eliminate and reverse trends in degradation of COOP network data. This activity will further strengthen the integrity of the nation's climate record by ensuring compliance with instrumentation and observer standards. 


\subsection{Historical Climatology Network Modernization}

The Historical Climatology Network (HCN) is a subset of COOP that contains high-quality data records over a long period. NOAA plans to modernize HCN (HCN-M), a process which will automate temperature and precipitation observations at 1,000 $\mathrm{HCN}$ sites. This will ensure the continuation of the nation's long-term regional climate record while enhancing the quality and sustainability of the record. This modernization is currently underway and will likely be complete within a decade.

\subsection{Regional Temperature and Precipitation Tables}

Customers have continuously requested that NOAA standardize its Regional Temperature and Precipitation Tables (RTP) product. Currently, these tables are issued locally with formats varying among offices, making it difficult for partners' automated routines to assimilate this information. Standardization of the RTP, which is populated primarily with daily maximum and minimum temperatures, snowfall and snow depth, and liquid equivalent of precipitation from COOP stations, is currently being evaluated and a nationally-consistent product is expected in 2008.

\subsection{Fischer \& Porter Upgrades}

NOAA's Hourly Precipitation Data network (HPD), a subset of approximately 2,500 COOP stations that measure precipitation for applications such as engineering, is experiencing problems related to the rain gauge and the automatic reader. Currently, HPD Fischer \& Porter (F\&P) rain gauges record 15-minute rainfall using a punch paper tape mechanism. This method is wrought with potential problems. Chief among them are that the tape can get stuck in the recording mechanism during periods of rainfall rendering a series of observations useless until a technician can correct the paper jam. Second, NCDC, which receives the paper tape for digitizing and populating the climate record, has only one remaining instrument capable of reading the tape. Efforts to procure replacement readers or parts to fix broken readers have been unsuccessful.

In order to maintain the climate record at the HPD sites and to ensure its continued viability, NOAA is taking steps to upgrade the F\&P rain gauge at all 2,500 HPD sites with a digital recording mechanism. While some upgraded gauges have been in place for a number of years, a re-engineering effort is under way which will ensure that: parts are available commercially off the shelf, the new rain gauge fits within the footprint of the existing gauge, and numerous suppliers can provide parts so there is no single point of failure. NWS expects to have all HPD sites upgraded within the next five years.

\subsection{Automated Snowfall and Snow depth}

In an effort to maintain the integrity of the climate record for snow, especially at automated or partially automated NOAA climate observing sites, NWS is examining the feasibility of utilizing automated snowfall and snow depth monitoring. Working with academia and volunteers in the WFOs, NWS has sensors in place and is testing their viability for operations. Preliminary results of the testing are promising and NWS fully expects to be able to move toward automated snow measurements in the near future at stations in networks such as the modernized Historical Climatology Network and LCD sites.

\section{Summary}

In recent years, there has been a heightened demand for timely, high quality climate observations. NOAA is responding to that heightened demand in several ways. First, the NWS established a Climate Services Division with a dedicated staff to help the agency respond to climate service issues in a timely, more coordinated fashion. Second, the NESDIS NCDC created a new NWS liaison, whose primary responsibilities was to strengthen NCDC associations with its climate partners, including the NWS. These changes set the stage for change.

Data stewardship partnerships between NWS, NCDC, the RCCs, and others blossomed. Critical data stewardship issues regarding data collection, quality control, and dissemination began receiving more attention with renewed vigor. New fully coordinated and improved data management procedures have been incorporated into NWS policy and field operations that now support the collection of data for not just meteorological applications but for climate also.

Additional activities are planned for the future, capitalizing on established momentum to further protect and improve the integrity of the nation's climate record. All data users benefit as well. 


\section{References}

American Association of State Climatologists. 2000. Defining the Role of the AASC Recognized State Climate Office in the National Climate Services Partnership. Asheville, NC.

Dutton, J.A. 2002. Opportunities and priorities in a new era for weather and climate services.

BAMS 83(9):1303-1311.

Karl, T.R., V.E. Derr, D.R. Easterling, C.K. Folland, D.J. Hoffman, S. Levitus, N. Nicholls, D.E. Parker, and G.W. Withee. 1995. Critical issues for long- term climate monitoring. Climatic Change 31:185-221.

Murnane R., M. Crowe, A. Eustis, S. Howard, J. Koepsell, R. Leffler, and R. Livezey; 2002. The weather risk management industry's climate forecast and data needs. BAMS 83(8):1193-1198.

Intergovernmental Panel on Climate Change. 2007. Mitigation of Climate Change. Bangkok, India.

Lott, N. and T. Ross. 2006. Tracking and Evaluating U.S. Billion Dollar Weather Disasters, 1980 - 2005. In the Proceedings of the $86^{\text {th }}$ Annual American Meteorological Society Meeting.

Available online at http://www1.ncdc.noaa.gov/pub/data/pap ers/200686ams1.2nlfree.pdf.

National Oceanic and Atmospheric Administration. 2003. New Priorities for the $21^{\text {st }}$ Century: NOAA's Strategic Plan MD. for FY 2003-2008. NOAA, Silver Spring,

National Research Council. 2001. A Climate Services Vision. The National Academies Press, Washington D.C.

National Research Council. 2003. Fair Weather: Effective Partnerships in Weather and Climate Services. The National Academies Press, Washington D.C.

National Weather Service. 1993. NWS Observing Handbook Number 6: COOP Operations. NOAA. Silver Spring, MD.

National Weather Service. 2003. National Weather Service Regional and Local
Climate Services: Implementation Plan. NOAA, Silver Spring, MD.

National Weather Service. 2005a. National Weather Service Instruction 10-2101: Climate Data Services. NWS. Silver Spring, MD.

National Weather Service, 2005b. National Weather Service Instruction 10-1003: General Instructions for TerrestrialBased In-Situ Instrument and Algorithm Intercomparisons for the Purpose of Climate Data Continuity. NOAA, Silver Spring, MD.

National Weather Service. 2006a. National Weather Service Instruction 10-1004: Climate Records. NWS. Silver Spring, MD.

National Weather Service, 2006b. NWS Regional and Local Climate Services Delivery Operations Document. NWS. Silver Spring, MD.

National Weather Service, 2007 (in draft). Improving the Quality of the Nation's

Climate Record: Toward a $21^{\text {st }}$ Century Cooperative Observer Network. NOAA. Silver Spring, MD.

Public Law 95-367. 1978. National Climate Program Act of 1978 (15 U.S.C. 2901, 2908). U.S. Congress.

Public Law 100-685. 1988. National Aeronautics and Space Administration Authorization Act. U.S. Congress.

Public Law 101-606, 1990. U.S. Global Change Research Act of 1990. U.S. Congress.

Redmond, K. 2006. Personal Communication.

Reeves, R.W. 2006. Personal Communication. 